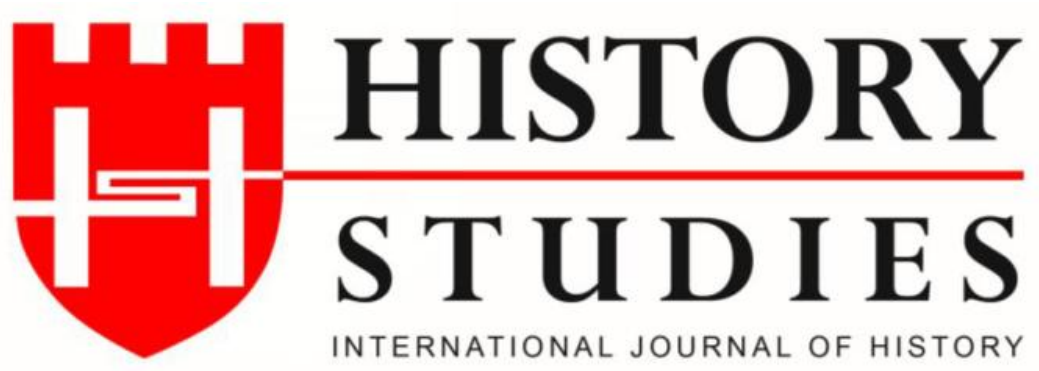

\author{
ISSN: 13094173 (Online) 1309 - 4688 (Print) \\ Volume 12 Issue 4, August 2020 \\ DOI Number: 10.9737/hist.2020.904 \\ Araştırma Makalesi \\ Makalenin Geliş Tarihi: 22.05.2020 Kabul Tarihi: 18.06.2020 \\ Atıf Künyesi: Gülnar Kara, “Bilinmeyen Bir Hun Prensi Jin Midi”, History Studies, 12/4, Ağustos 2020,
}

s. 1901-1914.

\title{
Bilinmeyen Bir Hun Prensi Jin Midi
}

\section{Jin Midi: An Unknown Hun Prince}

\author{
Doç. Dr. Gülnar Kara \\ ORCID No: 0000-0003-3283-7246 \\ Bitlis Eren Üniversitesi
}

Öz: Asya Hunlarının varoluşundan yıkılışına kadarki siyasî tarihi Çin kültür dairesi ile etkileşim içinde geçmiştir ve o kültürün gelişmesinde büyük rol oynamışlardır. Tarih boyunca farklı dönemlerde her iki milletten de karşı tarafa geçmiş ve hizmet vermiş önemli şahsiyetlerin bulunduğu tarihî bir hakikattir. Bunlardan birisi de aslen Hun veliaht prensi iken Han Hanedanı'na esir düşerek, sonrasında asaleti ve dürüstlüğü ile Han imparatoru Wu'nun sevgisini kazanmış, devlette yüksek mevkilere gelmiş olan Jin Midi'dir. Onun neslinden gelenler sonraki dönemlerde de isimlerinden söz ettirmiştir. Günümüzde de Jin soyadını taşıyan farklı ülkeden insanlar ecdadı olarak gördükleri Jin Midi'yi hatırlamaya devam etmektelerdir. Bu çalışmada neslinden önemli komutanlar ve devlet adamları çıkan ve Çin tarihinde önemli bir yer edinen Jin Midi'nin hayat serüveni Çin tarihî kayıtları ışığında araştırılacaktır.

Anahtar kelimeler: Han Hanedanı, Asya Hunları, Jin Midi, Xiutu Beyi, Jin Sülalesi.

\begin{abstract}
The political history of the Asian Huns from the existence to its collapse was in interaction with the Chinese cultural circle and played a major role in the development of that culture. It is a historical fact that there are important figures that have passed and served to the other side from both nations at different times throughout history. One of them is Jin Midi, who was originally captured in the Han Dynasty when he was the crown prince of Hun, and then gained the love of the Han emperor Wu with his nobility and honesty and came to high positions in the state. His descendants made a name for themselves in later periods. Today, people from different countries carrying the surname Jin continue to remember Jin Midi, who they see as their ancestry. In this study, the life adventure of Jin Midi, which has an important place in the history of China, will be investigated in the light of Chinese historical records.
\end{abstract}

Keywords: Han Dynasty, Asian Huns, Jin Midi, Xiutu Wang, Jin Family. 


\section{Giriş}

Han 汉 Hanedanı tahtına İmparator Wu 武帝 (MÖ. 140-86) çıkınca Çin'in kuzey komşuları olan Hunlarla 匈奴 ilgili politikası değişmeye başlamıştır. İmparator $\mathrm{Wu}$, ilk önce merkezî otoriteyi güçlendirerek ülkedeki siyasî durumu stabilize etmek için çeşitli idarî reformları hayata geçirmiştir. Dış politikada da önemli adımlar atılmıştı. Daha önceki Han Hanedanı imparatorları gibi Hunları heqin 和亲 politikas ${ }^{1}$ ile dizginlemek yerine aktif ve agresif politika uygulamayı seçmiştir. Bunun için olumlu şartlar da oluşmaya başlamıştı. İmparator Wen döneminde başlayan askerî reformlar tamamlanmış, orduda süvari birlikleri ve at yetiştiriciliği düzene koyulmuştu. Zhang Qian'ın 张寒 elçiliği ${ }^{2}$ neticesinde Çin'in batısındaki ülkelerin keşfedilmesi İmparator Wu'yu Hunları alt etme konusunda daha da umutlandırdı. Üstelik Wei Qing 卫青 ${ }^{3}$ ve Huo Qubing 霍去病 ${ }^{4}$ gibi yetenekli ve zafer hırsıyla yanıp tutuşan generaller ordunun başındaydılar. Hun cephesinde ise işler iyi gitmiyordu. MÖ. 126 yılında Maodun Chanyu'nün 冒顿单于 torunu olan Junchen Chanyu 军臣单于 vefat edince Sol Luli Beyi 左谷蟙王 ${ }^{5}$ olan kardeşi Yizhixie 伊稚斜 kendisini Chanyu ilan ederek merhum Chanyu'nun veliaht oğlu Yudan'a 於单 saldırarak mağlup etmişti. Yudan da çareyi Han Devleti’ne kaçmakta buldu. ${ }^{6}$ Böylece Hunlarda taht kavgaları başlamış oldu.

MÖ. 134 yılında imparator sarayında Hunlarla ilgili politikanın tartışıldığı toplantıda Han Anguo 韩安国 ${ }^{7}$ başkanlığındaki devlet erkânı tarafından Hunlarla barış ilişkilerine devam

\footnotetext{
${ }^{1}$ heqin, evlilik ile sağlanan barış anlaşmasıdır. $\mathrm{Bu}$ anlaşma çerçevesinde yabancı ülke hükümdarlarına bir Çin Prensesi eş olarak verilir ve bununla birlikte değerli eşyalar hediye edilirdi. Heqin anlaşmasının siyasî niteliği için bkz. Gülçin Çandarlığlu, İslam Öncesi Türk Tarihi ve Kültürü, Türk Dünyası Araştırmaları Yayınları, İstanbul 2003, s. 20; İbrahim Kafesoğlu, Türk Milli Kültürü, Boğaziçi Yayınları, İstanbul 1988, s. 62-63. Ayrıca heqin politikası hakkında ayrıntılı bilgi için bkz. Nurcan Türker, Han Hanedanlığ Döneminde Hunlarla Yürütülen Heqin Politikası (Akrabalık İle Sağlanan Barış Politikası) ve Sonuçları, (Ankara Üniversitesi Sosyal Bilimler Enstitüsü, Yayımlanmamış Doktora Tezi), Ankara 2013.

${ }^{2}$ Zhang Qian'ın batıya elçilik seyahati Shi Ji (SJ), 123. bölüm ve Han Shu (HS) 61. bölümde ayrıntılı anlatılmıştır. Bkz. Pulat Otkan, Tarihçinin Kayıtları’na (Shi Ji) Göre Hunlar, Haz. Giray Fidan, Türkiye İş Bankası Kültür Yayınları, İstanbul 2012, s. 95-115; Ayşe Onat, Çin Kaynaklarında Türkler, Han Hanedanı Tarihinde Batı Bölgeleri, Türk Tarih Kurumu Yayınları, Ankara 2012, s. 79-90. Zhang Qian, batıya seyahatinden döndükten sonra MÖ. 123-121 arasında Han Hanedanı'nın Hunlara karşı düzenlediği seferlere katılmış, bölgeyi iyi bildiğinden dolayı orduya otlak ve su bulma konusunda rehberlik yapmıştır (HS, 61. bölüm, s. 2661; Onat, age, s. 83).

${ }^{3}$ Wei Qing, İmparator Wu'nun eşi olan İmparatoriçe Wei'in üvey kardeşidir. İlk başta ablasının sayesinde imparator sarayında önemli mevkilere gelen Wei Qing, Hunlara karşı önemli zaferler kazanmıştır. Mezarı İmparator Wu'nun mezarının bulunduğu Maoling mezarlığında bulunmaktadır. Onun biyografisi için bkz. SJ, 111. bölüm, s. 29222947; HS, 55. bölüm, s. 2471-2494; Otkan, age, s. 131-154.

${ }^{4}$ Huo Qubing, Han Hanedanı döneminin ünlü komutanlarından biridir. Başkomutan Wei Qing'in de yeğeni olan Huo Qubing çok genç yaşta Hunlara karşı zaferleriyle ünlenmiştir. Genç yaşta vefat eden Huo Qubing'in mezarı İmparator Wu'nun mezarının bulunduğu Maoling mezarlığında bulunmaktadır. Mezarının yanına Hunlara karşı zaferini simgeleyen "Hun'u ezen at" heykeli yaptırılmıştır. Onun biyografisi için bkz. SJ, 111. bölüm, 2922-2942; HS, 55. bölüm, s. 2471-2494; Otkan, age, s. 131-154).

5 Hunların devlet hiyerarşisinde önemli bir makamdır. Sonraki Han Hanedanı Tarihi'nde "Hunların devlet teşkilatının üst düzey makamları arasında Sol Bilge Beyi, ondan sonra sırasıyla Sol Luli Beyi, Sağ Bilge Beyi ve Să̆ Luli Beyi gelmektedirler ve bunlar "dört boynuz" olarak adlandırılmaktadır. Onların hepsi Chanyu'nun oğulları ve kardeşleridir ve yaş durumuna göre Chanyu oluyorlar, " şeklinde kaydedilmiştir (Hou Han Shu (HHS), 79. bölüm, s. 2944).

${ }^{6}$ İmparator $\mathrm{Wu}$, Yudan'a She'an Markisi 涉安侯 unvanı takdim etmişti, ancak genç prens birkaç ay sonra vefat etmiştir (SJ, 110. bölüm, s. 2907; HS, 94/a. bölüm, s. 3767; Otkan, age, s. 81; Ayşe Onat, Sema Orsoy, Konuralp Ercilasun, Han Hanedanı Tarihi, Hsiung-nu (Hun) Monografisi, Türk Tarih Kurumu Yayınları, Ankara 2015, 2. bask1, s. 25.

${ }^{7}$ Han Anguo, İmparator Jing ve İmparator Wu dönemlerinin önemli devlet adamı ve komutanlarından birisidir. Onun biyografisi için bkz. SJ, 108. bölüm, s. 2857-2866).
} 
edilmesi gerektiği ileri sürülmesine rağmen Wang Hui 王恢 ${ }^{8}$ ve taraftarlarının Hunlara savaş1 destekleyen görüşü kabul edilmiştir. ${ }^{9}$ Böylece MÖ. 129 yılının ilkbaharında dört kola bölünen 40.000 kişilik Han ordusu aynı anda Hunlara karşı sefere çıkmıştır. Ancak bu sefer Han ordusu için başarısızlıkla sonuçlanmıştı. İki Han ordusu yenilgiye uğramıştır. Bu zaferden güç alan Hunlar da sınır eyaletlere saldırılarını sıklaştırmıştır. MÖ. 127 yılında Han ordusu tekrar bir sefer düzenlemiş ve başarılı olmuştur. Başkomutan 大将军 Wei Qing'in ordusu Ordos bölgesini ele geçirmiş, böylece Hunların başkente saldırı tehlikesini ortadan kaldırmıştır. Ordos bölgesinde askerî üs olarak kullanılması maksadıyla Shuofang eyaleti 朔方郡 ${ }^{10}$ kurulmuş ve İmparator Wu'nun emriyle oraya 100.000 yoksul Çinli yerleştirilmiştir. ${ }^{11}$ Sonraki yıllarda neredeyse İmparator Wu'nun ölümüne kadar Han-Hun savaşları şiddetlenerek devam etmiştir. Bu savaşların birinde Jin Midi'nin 金日磾 ${ }^{12}$ babası olan Xiutu Beyi 休屠王, Huo Qubing'den ağır yenilgi almıştı. Xiutu Beyi, bu dönemde Hunye Beyi 昆邪王 ${ }^{13}$ ile birlikte Hunların batı bölgelerinin hükümdarı idi. ${ }^{14} \mathrm{Bu}$ olay Çin kaynaklarının birçoğunda ayrıntılarıyla anlatılmıştır. Tarihçinin Kayıtları'nda (SJ) anlatıldı̆̆ında göre, MÖ. 121 yılının ilkbaharında çevik kuvvetler birliği komutanı Huo Qubing 10.000 kişilik ordusuyla Longxi'den 陇西 ${ }^{15}$ çıkarak Hunlara saldırmış, 8.000'den fazla ${ }^{16}$ Hun'u etkisiz hale getirmiştir. Ayrıca Xiutu Beyi'nin Gök Tanrısına ibadet için kullandığı altın adam heykelini ${ }^{1{ }^{7}}$ ele geçirmiştir. Aynı yılın yaz mevsiminde yine Qilian Dağları 祁连山 ${ }^{18}$ civarında Hunları tekrar mağlup ederek 30.000'den

Volume 12

Issue 4

August

2020 ${ }^{8}$ Han Hanedanı döneminin önemli devlet adamlarının birisiydi. Kendisinin ısrarla savunduğu Hunlara karşı seferde
garnizon birliği komutanı olarak görevlendirilmiş, ancak başarısız olduğu için mahkemeye çıarılmış ve idam cezası
alacağını duyunca intihar etmiştir (HS, 52. bölüm, s. 2403-2405).
${ }^{9}$ Han Anguo ve Wang Hui'nin tartışması için bkz. HS, 52. bölüm, s. 2398-2403.
${ }^{10}$ Shuofang, Sarı Nehrin kuzey büklümünde bir karakoldur. Wei Qing' in zaferi neticesinde Hunların Baiyang 白羊
ve Loufan 楼烦 kabileleri topraklarını terk etmeye zorlanmış ve çok sayıda kişi ve hayvan ele geçirilmiştir. Bu
başarılarından dolayı Wei Qing'e Changping Markisi 长平侯 unvanı ve 3.800 hanelik tımar bahşedilmiştir (SJ, 111 .
bölüm, s. 2923).

${ }^{11}$ Tilla Deniz Baykuzu, Asya Hun Imparatorluğu, Kömen Yayınları, Konya 2012, s. 79.

${ }^{12}$ Jin Midi’nin isminin birinci karakteri (日) mi 密 şeklinde okunmalıdır.

${ }^{13} \mathrm{Bu}$ beyin isminin ilk karakterinin kun okunuşu da mevcuttur. Hunye Beyi, Xiutu Beyi ile birlikte MÖ. 121 yılında Çinli General Huo Qubing'den ağır yenilgi alarak, sonrasında Han Hanedanı'na teslim olmuştu. Onun kabilesiyle teslim olması hem Han Hanedanı hem Hun Devleti tarihinde önemli bir olaylardan biri olmuştur ki Çin kaynaklarının birçoğunda bu olaydan bahsedilmiştir. Hunye Beyi'nin teslim olmasıyla Han Hanedanı'nın Gansu koridoruna sahip olmasının önü açılmış oldu.

${ }^{14}$ Burası Gansu bölgesi idi. Eskiden Yuezhi'ler 月氏 ve Wusun'ların 乌孙 yurdu olan bu bölge, her iki halkın da Hunlar tarafından batıya sürülmesinden sonra Hunların eline geçmişti. Hunların Xiutu Beyi’nin Yuezhilerin, Hunye Beyi'nin ise Wusun'ların yurduna yerleştirildiği anlaşılmaktadır (Bahaeddin Ögel, "Çin Kaynaklarına Göre Wusunlar ve Siyasî Sınırları Hakkında Bazı Problemler”, Ankara Üniversitesi Dil ve Tarih-Coğrafya Fakültesi Dergisi, VI/4, 1948, s. 265).

Hexi (Gansu) koridorunun batısı Hunye Beyi’nin, doğu kısmı ise, Xiutu Beyi’nin egemenliği altındaydı. Gansu, günümüzde Çin'in kuzey-batısında bir eyalettir. Gansu adı ilk olarak Moğolların Yuan Hanedanı döneminde (12061368) kullanılmaya başlamışır. O zamana kadar Hexi koridoru olarak biliniyordu ve Han Hanedanı döneminde bu koridor boyunca Çin Seddi genişletilmiş ve Yumenguan 玉门关 ve Yanguan 阳关 kaleleri ile güçlendirilmiştir.

15 Qin 秦 Hanedanı döneminde kurulmuş bir eyalettir. Günümüzdeki Gansu eyaletinin güney-doğusunda bulunuyordu.

${ }^{16}$ Bu rakam SJ'de 18.000 olarak verilmiştir (SJ, 110. bölüm, s. 2908).

${ }^{17}$ Meng Kang'ın 孟康 açıklamasında göre, Hunlar eskiden Ganquan Dağları 甘泉山 eteklerinde Gök Tanrısına kurban veriyorlardı. Qin Hanedanı bu toprakları zapt edince tören yeri Xiutu Beyi'nin topraklarına nakledilmiş, ibadet için kullanılan altın adam heykeli bu şekilde Xiutu Beyi'nin elinde bulunuyordu. Yan Shigu'nun 顔師古 açıklaması ise, Hunların altın bir insan heykeli yaptırarak ona ibadet ettikleri yönündedir, hatta güya Buda heykeline ibadet etme bu uygulamadan gelmiştir (HS, 94/a. bölüm, s. 3769, not. 1).

${ }^{18}$ Qilian Dağları, Çin'de Kunlun Dağları'nın kuzeyinde bulunan sıradağlardır. Burası Hunların önemli yurtlarından biri olmalıdır. General Huo Qubing'in zaferinden sonra Qilian Dağlarını kaybeden Hunlar bunun için hüzünlü bir şiir 
fazla kişiyi etkisiz hale getirmişti. Sonbaharda Hun Chanyu'su üst üste Han ordusundan yenilgiye uğrayan Hunye Beyi ve Xiutu Beyi’ne çok kızmış ve karargâhına çağırmıştı. İdam edileceği korkusu yaşayan iki bey sınıra haber göndererek Han Devleti'ne teslim olmak istediklerini bildirmişlerdir. ${ }^{19}$ İmparator $\mathrm{Wu}$, onların bu niyetlerinin doğru olup olmadı̆̆ını anlamak için Huo Qubing'i ordusuyla göndermiştir. Sonrasında kararından vazgeçen Xiutu Beyi, Hunye Beyi tarafından öldürülmüş, Hunye Beyi onun kabilesini kendi halkıyla birleştirerek 40.000 kişiyle Han Devleti'ne teslim olmuştur. ${ }^{20}$ Han Hanedanı Tarihi'nin kayıtlarına göre aslında Huo Qubing'in de hileye başvurduğunu görüyoruz. İmparatorun gözüne girmek için teslim olanların sayısı 100.000 olarak gösterilmiştir. ${ }^{21}$ İmparator $\mathrm{Wu}$, teslim olan Hunye Beyi'ni Tayin Markisi 漯阴侯 unvani $^{22}$ ve 10.000 hanelik tımar ile mükâfatlandırmıştır. ${ }^{23}$ Aslında bu savaşlar Han Hanedanı için çok pahalıya mal olmuştur. İmparator teslim olan Hunları taşımak için 20.000 at arabası göndermiş, hazineden yüklü miktarda para harcamıştı. ${ }^{24}$ Teslim olan Hun kabileleri beş sınır vilayetine yerleştirilmiştir. ${ }^{25}$ Böylece eskiden Hunye Beyi ve Xiutu Beyi'nin toprakları olan yerler boş kalmıştır. ${ }^{26}$ Zhang Qian, imparatora Hunlardan boşalan topraklara Wusun'ların 乌孙 ${ }^{27}$ yerleştirilmesi ve Han Devleti ile dostluk ilişkileri kurmaları için onların ikna edilmesini önermiş ve "Eğer onlar ikna olurlar ve Wusun'larla birleşirsek Hunların sağ kolu kesilmiş olur," demiştir. Bundan dolayı İmparator Wu, Zhang Qian'1 tekrar batıya göndererek (MÖ. 117) Wusun'ları Hunlardan boşalan topraklara yerleşmeleri için ikna etmeye çalıştıysa da başarılı olamamıştır. ${ }^{28}$

Bundan sonra Han Hanedanı Hunlardan boşalan topraklarda hâkimiyet kurmak ve kalıcı olmak için buralarda Çinli çiftçilere araziler tahsis ederek tarımla uğraşmaları sağlanmıştır. Bunu hayata geçirmek için devlete karşı suç işleyip mahkûm olanlar ve asayişi bozan eşkıyalar bölgede oluşturulan askeri çiftliklere yerleştirilerek sınırda bir güvenlik kordonu oluşturulmaya çalışılmıştır. Bu iskân faaliyetleri neticesinde idarî taksimat gerçekleştirilerek bölgede Wuwei 武威, Zhangye 張掖, Dunhuang 敦煌 ve Jiuquan 酒泉 olmak üzere dört eyalet kurulmuştur. Bunlardan yaklaşık MÖ.101 yılında kurulmuş olan Wuwei eyaleti 武威郡, eski Xiutu Beyi’nin toprakları idi. Wuwei eyâletinde 17.581 hane, 76.419 kişi ve 10 kaza vardı. Kazalardan bir tanesinin adı Xiutu'nun ismini taşıyordu. ${ }^{29}$ Bunun dışında aynı ismi taşıyan

söylemişlerdi (V. S. Taskin, Materialı Po İstorii Syunnu, Nauka, Moskva 1968, s. 147-148, 179, 183). Ayrıca Huo Qubing'in mezarının da Qilian Dağları şeklinde yapılması (SJ, 111. bölüm, s. 2939) da bu dağların Hunlar için önemini göstermektedir. Nedense bu cümle Pulat Otkan'ın Türkçe çevirisinde yer almamaktadır (Otkan, age, s. 147). Huo Qubing'in mezarı etrafında çok sayıda taş heykeller yer almaktadır. Özellikle Hun'u ezen at heykeli Han Hanedanı'nın Hunları yendiğinin bir sembolü olarak görülmektedir (R. V. Vyatkin, Muzei i Dostoprimeçetel'nosti Kitaya, Moskva 1962, s. 18-20, Baykuzu, age, s. 82, not. 139).

${ }^{19}$ HS, 94/a. bölüm, s. 3769.

${ }^{20}$ SJ, 110. bölüm, s. 2909.

${ }^{21}$ SJ, 110. bölüm, s. 2909, HS, 94/a. bölüm, s. 3769, Onat, Orsoy, Ercilasun, age, s. 27.

${ }^{22}$ Tayin, günümüzde Çin'in Shangdong ilinin Yucheng ilçesinde bulunan ilçe merkezidir.

${ }^{23}$ SJ, 111. bölüm, s. 2933.

${ }^{24}$ SJ, 30. bölüm, s. 1432; Huan Kuan, Yan Tie Lun, 44. bölüm.

http://www.guoxue.com/zibu/zhajia/yantielun/ytl_044.htm (E. T. 15.01.2020).

${ }^{25}$ Rus bilim adamı Taskin'e göre bu beş vilayet Longxi, Beidi, Shangjun, Shuofang ve Yunzhong'dur (Taskin, 1968, s. 165, dipnot. 26). Batı Han Hanedanı döneminde yazılmış olan Huan Kuan'ın 桓宽 Tuz ve Demir ile Illgili Sohbetler 盐铁论 isimli eserinin 44. bölümünde nedense bu vilayetler beş vassal ülke (shuguo 属国) şeklinde verilmiştir: “浑耶率其众以降, 置五属国以距胡...”. http://www.guoxue.com/zibu/zhajia/yantielun/ytl_044.htm (E. T. 15.01.2020).

${ }^{26} \mathrm{HS}, 61$. bölüm, s. 2661; Onat, age, s. 83.

${ }^{27}$ Hunlar dönemindeki göçebe kavimlerden birisidir.

${ }^{28}$ SJ, 123. bölüm, s. 3168-3169; HS, 61. bölüm, s. 2692.

${ }^{29}$ Xiutu kazası, Wuwei şehrinin biraz kuzeyinde Gu Irmağı 谷水 yakınlarında bulunuyordu (Zhongguo Lishi Ditu Ji 中国历史地图集, Red. Tan Qixiang 谭其骧, 1985, s. 33-34). 
gölet 休屠泽 ve kale 休屠城 de vard1. ${ }^{30}$ Sonraki Han Hanedan Tarihi'nde (HHS) “Xiutu karışık Huları” 休屠各胡 tabiri bulunmaktadır ve onların Bing vilâyeti 并州 Genel Valisine saldırdıkları, sonrasında Güney Hunların sol kanadıyla birleşerek onların Chanyu'sünü öldürdükleri kaydedilmiştir. ${ }^{31}$ Yani Xiutu Beyi'nin kabilesinin sonraki dönemlerde de tarih sahnesinden henüz silinmediğini görüyoruz.

\section{Jin Midi’nin Han Hanedanı Sarayına Esir Düşmesi ve Hayatı}

Jin Midi, babası Xiutu Beyi Han ordusundan yenilgiye uğrayıp Chanyu'nun gazabını üzerine çektiği zaman 14 yaşında bir veliaht prensti. Babası, Hunye Beyi ile birlikte Han Devleti'ne teslim olmaya karar verdiyse de sonrasında bundan vazgeçmiş ve bundan dolayı Hunye Beyi tarafindan öldürülmüştü. Böylece genç prens, annesi ve küçük kardeşi ile esir alınmış, Han sarayında at bakıcısı olarak hizmete verilmiştir. Zamanla asaletli davranışları ve çalışkanlığı ile İmparator Wu'nun dikkatini çekmeyi başarmış, bundan sonra devlet makamlarında hızlı bir şekilde yükselmeye başlamıştır. Babasının elinde bulunan Hunların ibadet için kullandığı altın adam heykelinden dolayı İmparator Wu kendisine Jin 金 (altın) soyadını vermiştir. Özellikle Ma kardeşlerin ${ }^{32}$ imparatora suikastını önledikten sonra saraydaki yeri sağlamlaşmıştır. İmparator Wu ona o kadar güveniyordu ki ölümünden önce çocuk yaştaki veliahdının naiplerinden birisi olarak görevlendirmiştir. Bu görevi de layığıyla yerine getiren Jin Midi, imparatorun vefatından bir yıl sonra hayata gözlerini yummuştur.

Jin Midi, sonraki dönemlerde de örnek alınacak kişi olarak görülmüştür. Jin Hanedanı Tarihi'nde (JS) 晋书 Han Devleti'nin ${ }^{33}$ kurucusu Hun asıllı ve Maodun Chanyu'nün neslinden gelen Liu Yuanhai 刘元海 ve onun akrabası Liu Xuan'ın 刘宣 biyografilerinde ${ }^{34}$ onların davranışlarından övgüyle bahsedilirken Jin Midi ile karşılaştırılmıştır. ${ }^{35}$

Volume 12

Bundan sonraki dönemde Jin kardeşlerin sülalesi sarayda önemli mevkilere gelmişler; Han Hanedanı Tarihi'nin verdiği bilgilere göre yedi nesil boyunca saraya hizmet etmişler, yüksek mertebelerini ve itibarlarını muhafaza etmişlerdir. Araştırmacı Chen Sanping'e göre, ünlü Çin tarihçisi, aynı zamanda Han Hanedanı Tarihi'nin (HS) müellifi olan Ban Gu da anne tarafından Jin Midi'nin kardeşi Jin Lun'un soyundan olabilir. ${ }^{36}$ Elbette bu daha detaylı araştırılması gereken konulardan biridir. Ancak bu tabloda $\ddot{U}_{c}$ Krallık Kayıtları 三國志 (San Guo Zhi) eserinde adı geçen Jin Midi'nin soyundan olduğu bilinen Jin Xuan 金旋 (öl. 209) ve oğlu Jin Yi'nin 金禕 isimleri geçmemektedir. ${ }^{37}$ Bu kaynakta (SGZ) Wuling Genel Valisi 武陵太守 iken Jin Xuan'ın diğer valiler ile birlikte Liu Bei’ye 刘备 ${ }^{38}$ teslim olduğu kaydedilmiştir. Aynı metnin açıklamasında Jin Xuan'un oğlu Yi'nin 禕 ismi de geçmektedir. ${ }^{39}$ 14. yüzyılda Luo

\footnotetext{
${ }^{30}$ HS, 28/b. bölüm, s. 1612 .

${ }^{31}$ HHS, 8. bölüm, s. 355 .

${ }^{32}$ Onlar hakkında aşağıda bilgi verilmiştir.

${ }^{33}$ Liu Yuanhai kendi kurduğu devlete Çin'in Han Hanedanı ile akrabalığından dolayı Han ismini vermiştir. Ancak sonrasında tahta geçen akrabası Liu Yao'nun devletin ismini Zhao olarak değiştirmesinden dolayı araştırmacılar genelde bu devleti Önceki Zhao Devleti olarak da adlandırıorlar.

${ }^{34}$ Liu ailesi için bkz. Gülnar Kara, "Hunlar Tarafından Kurulan Önceki Zhao Veya Han Zhao Devleti Hükümdarlarının Biyografileri (Jin Sülalesi Tarihine Göre)", Türk Dünyası Araştırmaları Dergisi, 110 (216), İstanbul 2015, s. 19-37.

35 Jin Shu (JS) 晋书, 101: “... 刘元海容仪机鉴，虽由余、日磾无以加也;“宣若遇汉武，当逾于金日磾也” JS, 101.bölüm, s. 2646, 2653).

${ }^{36}$ Jin sülalesinin şecere tablosu aşağıda verilmiştir. Bkz. Chen Sanping, age, p. 36.

37 Jin Xuan ve Jin Yi hakkında bkz. Rafe de Crespigny, A Biyographical Dictionary of Later Han to the Three Kingdoms (23-220 AD), vol. 19, Brill, Leiden-Boston 2007, p. 381.

${ }^{38}$ Liu Bei (162-223), Üç Krallık döneminin güçlü komutanlarındandır ve Shu Beyliği’nin kurucusudur.

${ }^{39}$ SGZ, 32. bölüm, s. 879-880, not. 1 .
} 
Guanzhong 罗贯中 tarafından kaleme alınan $\ddot{U} c ̧$ Krallık Hikâyeleri 三国演义 romanında (Sanguo Yanyi) ise, Jin Xuan'ın kendisine karşı savaşa çıkan Liu Bei'in generali ile çatışmada öldürüldüğü ve ona bağlı eyaletin Liu Bei'in egemenliği altına geçtiği bildirilmiştir. Jin Yi 金禕 ise, 218 yılında taraftarlarıyla Wei 魏 Hanedanı kurucusu Cao Cao’a 曹操 karşı isyan bayrağı çekmiş, ancak yenilgiye uğrayıp idam edilmiştir. ${ }^{40}$

$\mathrm{Bu}$ aile fertleri sonraları Tuge 屠各 kabilesi içinde ve günümüzdeki Gansu'nun 甘肃 Pingliang 平凉 ${ }^{41}$ havalisinde karşımıza çıkmaktadır. Jin Hanedanı Tarihi (JS) ve Wei Hanedanı Tarihi'nde (WS) 3. yüzyıldan sonra Pingliang'daki Tuge halkının beyleri Jin Xi 金熙, Jin Bao 金豹, Jin An 金岸 gibi kişilerin isimleri geçmektedir ve onların Jin sülalesine mensup oldukları bildirilmiştir. ${ }^{42}$ Kuzey Hanedanları Hu Aileleri Araştırmaları isimli eserde (Bei Chao Hu Xing Kao) Pingliang'daki Jin ailesinin Hunların Xiutu Beyi'nin soyundan ve Tuge klanından 屠各族 oldukları kaydedilmiştir. ${ }^{43}$ Bu kaynaklarda bahsi geçen kişilerden Pinliang Hu'ları, Pingliang Xiutu veya Xiutu Hu'lar ${ }^{44}$ şeklinde bahsedilmiştir. Jin Hanedanı Tarihi'nin (JS) 97. bölümünde de kuzeydeki Di'lerin 北狄 ${ }^{45}$ (yani Hunların) 19 kabileye bölündügünden bahsederken en güçlü ve asilinin Tuge kabilesi olduğu ve Chanyu'lerin bu kabileden çıktığ 1 bildirilmiştir. $^{46}$

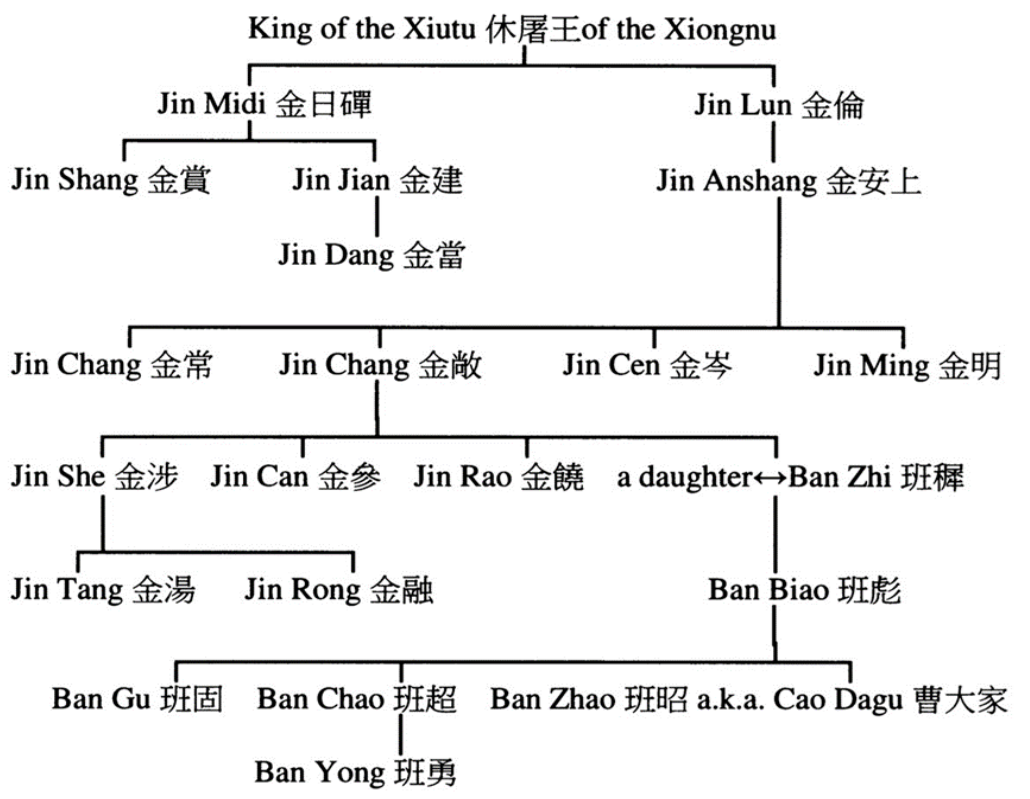

\footnotetext{
${ }^{40}$ Sanguo Yanyi (SGYY), 53. bölüm http://www.guoxue.com/minqingstory/sgyy/sgyy_053.htm (E. T. 15.01.2020).

41 Gansu'nun doğusunda bulunan Pingliang, Han Hanedanı döneminde Anding eyaletine 安定郡 bağlıydı. Günümüzde Langzhou'un doğusundadır. Sui Hanedanı Tarihi'nde karşımıza Türklerin ortaya çıkış efsaneleri ile ilgili bir bölge olarak çıkmaktadır (Sui Shu (SS), 84. bölüm, s.1863).

${ }^{42}$ JS, 116. bölüm, s. 2967; 117. bölüm, s. 2977, WS, 4/a. bölüm, s. 74, Yao Weiyuan 姚薇元, Bei Chao Hu Xing Kao 北朝胡姓考 (BCHXK), Zhonghua shuju, Beijing 1962, s. 286.

${ }^{43}$ BCHXK, age, s. 286.

${ }^{44}$ Çin araştırmacılar Xiutu Beyi’ne bağlı kabilelerin Gansu'nun eski sakinleri olan Yuezhi'ler ile karışık yaşadıklarını ileri sürerek onlar için genelde Hu tabiri kullanmaktalardır.

${ }^{45}$ Kuzeydeki ya da kuzey Diler. Çin'in dört tarafının yabancı kavimlerle çevrili olduğu görüşü Çin'de kadim zamanlardan beri hakim olmuştur. Kuzeydeki Diler (Bei Di) anlamında genelde Hun kabileleri söz konusu olmuştur. ${ }^{46}$ JS, 97. bölüm, s. 2550.
} 
Muhtelif kaynaklarda ailenin Longxi'deki 陇西 mensuplarına Xiutu Hu'ları, Pingliang'dakilere Pingliang Xiutu veya Pingliang Hu'ları denilmiştir. ${ }^{47} \mathrm{Bu}$ da aklımıza Sui Hanedanı Tarihi'ndeki (SS) “Türklerin 突厥 kökeni Pingliang'daki karışık Hular 平凉杂胡 idi” cümlesini getirmektedir. ${ }^{48}$ Türk (Tujue) ve Tuge kelimelerinin arasındaki benzerlik ve Xiutu Beyi'ne bağlı kabileler, Tuge kabilesi ve Türkler arasındaki ilişki dikkat çekicidir. ${ }^{49}$ Jin ailesi dışında Tuge kabilesinden Zhang 张, Cheng 成, Jin 靳, Dong 董gibi Hun kökenli ailelerin de çıktığını da hatırlatmak da yerinde olacaktır. ${ }^{50}$

\section{Jin Midi’nin Biyografisi (Han Hanedanı Tarihi, 68. bölüm)}

Jin Midi'nin 金日磾 ikinci ismi Wengshu 翁叔 idi. Evvela Hunların Xiutu Beyi’nin veliaht oğluydu. İmparator $\mathrm{Wu}$ [döneminin] yuanshou 元狩 [saltanat devresinin] ortasında (122-118) çevik süvariler [birliğinin] komutanı 票骑将军 Huo Qubing, ordusuyla Hunların batı kanadına saldırı düzenlemiş, çok sayıda kafa keserek, Xiutu Beyi'nin elinde bulunan Gök Tanrısına ibadet için kullanılan altın adam heykelini ele geçirmişti. Aynı yılın yaz mevsiminde [MÖ. 121] çevik süvariler [birliği komutanı] tekrar Juyan 居延 [eyâletinden] sefere çıkarak Qilian Dağları [bölgesine] saldırı düzenlemiş ve büyük bir zafer kazanmıştı. Bundan dolayı Chanyu, ${ }^{51}$ batıda ikamet eden Hunye ve Xiutu'nun Han [ordusundan] defalarca yenilgi almalarına kızmış, iki Beyi de çağırarak idam etmeyi planlamıştı. [Bunu öğrenince] Hunye ve Xiutu, Han [Devleti'ne] teslim olmayı düşündüler. Sonrasında Xiutu Beyi [bu kararına] pişman olmuştu. [Bundan dolayı] Hunye Beyi onu öldürdü ve onun halkını kendi kabilesiyle birleştirerek Han [Devleti'ne] teslim oldu. [Bunun için] Hunye Beyi'ne Lie Markisi 列侯 unvani $^{52}$ takdim edildi.

[Jin] Midi’nin babası (yani Xiutu Beyi) teslim olmadan öldürüldüğünden dolayı yanzhi 阏氏 olan annesi ve küçük kardeşi Lun 伦 ile birlikte hepsi devlete [köle olarak] hizmete verildiler. [Jin Midi], imparator sarayına at bakıcısı olarak görevlendirildi. Bu sırada kendisi 14 yaşındaydı.

Aradan uzun bir zaman geçmişti, İmparator Wu teftişe çıkmış ve atlarını görmeye karar vermişti. İmparatorun yanında haremindeki cariyeler vardı. [Jin] Midi ve birkaç düzine kişiden oluşan at bakıcıları, atları Majestelerinin önünden geçirmekteydiler. At bakıcılarının hepsi [kendilerini cariyelere] gizlice bakmaktan alıkoyamadılar. Sadece [Jin] Midi bunu yapmamıştı. Jin Midi, 8 chi, 2 cun uzunluğundaydı, ${ }^{53}$ yüz ifadesi ve görünümü çok ciddiydi. [Ayrıca] atları çok besili ve bakımlıydılar. [Bundan etkilenen] imparator sorular sormaya başlayınca kökleri [hakkında] tüm gerçekleri anlattı. [Karşısında] haysiyetli bir adam olduğuna karar veren imparator hemen [onun] banyo yapmasını ve resmî bir memur kıyafeti giymesini emrederek

\footnotetext{
${ }^{47}$ Kürşat Yıldırım, Bir Zamanlar Türk İdiler, Türk Kökenli Çin Aileleri, Ötüken Yayınları, İstanbul 2017, s. 48.

${ }^{48}$ Sui Shu (SS), 84. bölüm, s. 1863.

49 Sui Hanedanı Tarihi, Türklerin (Aşina) erken tarihini, 308-460 yıllarında Çin topraklarında bulunan Hun Devletlerinin tarihiyle yakından bağlantılı yapmaktadır (H. Cordier, Histoire Generale de la Chine, tome I, Paris 1920, p. 340-384; W. M. McGovern, The Early Empires of Central Asia: A Study of the Scythians and the Huns and the Part They Played in World History, with Special Reference to the Chinese Sources, The University of North Carolina Press, New-York 1939, pp. 311-355).

${ }^{50}$ BCHXK, age, s. 278-279; 283-284; 284-286; 287-288.

${ }^{51}$ Yukarıda bahsi geçen Maodun Chanyu'nun torunu Yizhixie Chanyu'dur.

${ }^{52}$ Han Hanedanı döneminde tımar olarak bir kaza halkı verilen asalet unvanıdır.

${ }^{53}$ Han Hanedanı döneminin uzunluk ölçü birimleridir. 1 cun 2,4 cm, 1 chi ise, 10 cun idi. Bu durumda Jin Midi'nin boyunun uzunluğu $196,8 \mathrm{~cm}$. olmalıdır.
} 
majian 马监 ${ }^{54}$ olarak atad1. Zamanla shizhong 侍中, ${ }^{55}$ fuma duwei 驸马都尉, ${ }^{56}$ guanglu dafu 光禄大夫 ${ }^{57}$ makamlarına kadar yükseldi.

Jin Midi, imparatorun yakın çevresine girince de hiçbir zaman saygısızlık veya hata yapmamıştır. İmparator onu çok sever ve güvenirdi. Birkaç defa [ödül olarak] 1.000 altın takdim etmiştir. Saray dışında imparatora eşlik eder, sarayda da her zaman onun yanında olurdu. İmparatorun akrabaları ve yakın çevresi birçok defa gizlice: "Göğün Oğlu tesadüfen Hu bir çocuğu buldu, ona saygı gösteriyor, onurlandırıyor," diye homurdanıyorlardı. Onların sözleri kulağına gelince imparator Jin Midi’ye daha da iyi davranmaya başladı.

[Jin] Midi'nin annesi her iki oğluna çok özenle terbiye vermişti [ki onların davranışları kusursuz idiler]. İmparator, bunu duyunca övgüler düzmüş, [kadın] hastalanarak vefat ettiğinde Ganquan Sarayına 甘泉宫 ${ }^{58}$ “Xiutu Beyi’nin Yanzhi'si” 休屠王阏氏 yazısıla onun resmini yaptırmıştı. [Jin] Midi, bu tabloya her baktığında [saygıyla] eğilir, vatanına özleminden gözyaşı döker, sonra çıkıp giderdi. [Jin] Midi'nin iki oğlu [imparatora] çok bağlıydılar ve imparatoru eğlendirir, ${ }^{59}$ daima yanında bulunurlardı. Bir gün oğlanlardan birisi imparatora boynunun arkasından sıkıca sarılınca imparatorun önünde duran [Jin] Midi bunu fark ederek oğluna kızgın bir bakış atmıştı. Oğlan da "Babam bana kızdı!" diye yüksek sesle ağlayarak uzaklaşmıştı. İmparator da [Jin] Midi’ye "Benim oğluma neden kızdın?” diye çıkışmıştı. Daha sonra [bu] oğlan büyüdüğünde ölçüsüz davranmaya başladı, Majestelerinin cariyeleriyle eğlenerek [zaman geçiriyordu]. [Jin] Midi oğlanın ahlaksız davranışlarına tanık olunca [öfkelenerek] onu öldürdü. Bu [Jin] Midi’nin büyük oğluydu. İmparator bunu duyunca çok öfkelendi. [Jin] Midi, başını secdeye vurarak özür diledi ve oğlanı neden öldürdügünü açıkladı. İmparator kederlenerek [ölü genç için] ağladı, ama kalbinde [Jin] Midi’ye saygı duymuştu.

Evvela Ma Heluo 䒭何罗 ${ }^{60}$ ile Jiang Chong 江充 $^{61}$ iyi arkadaş idiler. [Sonrasında Jiang] Chong, [imparatorun İmparatoriçe Wei’den 卫 doğan] veliaht oğlunu etkisiz hale getirmişti. Veliaht Prens cezalandırıldığı zaman sıkı çaba sarf ettiğinden dolayı [Ma] Heluo'nun küçük kardeşi [Ma] Tong'a 通 da unvan takdim edilmişti. Sonrasında imparator veliaht Prens'in suçsuz olduğunu öğrendi ve [Jiang] Chong'un tüm sülalesi ve suç ortaklarını yok etti. [Ma] Heluo ve küçük kardeşi [bu olayın kendilerine sıçrayacağından] korktular ve gizlice isyan planı yaptılar. [Jin] Midi, onların olağandışı bir şey planladıklarını fark etmiş, kalbine şüphe girmişti.

\footnotetext{
${ }^{54}$ At yetiştiriciliği ve islahından sorumlu memuriyet makamıdır. Hucker, Directorate of Horses olarak çevirmiştir. Muhtemelen Taipu (imrahor) teşkilatına bağlı bir memuriyetti (C. O. Hucker, A Dictionary of Official Titles in Imperial China, Southern Materials Center, California 1985, p. 326).

${ }^{55}$ Saray görevlisidir. Bu makam için bkz. Hucker, age, p. 423. Shizhong, imparator ve maiyetini takip eder ve çeşitli hizmetlerini görürdü. Han Hanedanı döneminde ek görev olarak yapılıyordu ve zaten bir makam sahibi olan kimseler görev yapıyordu. Dolayısıyla bu makamda birkaç düzine kişi görev yapabiliyordu (Taskin, age, 1968, s. 162, not. 7). 56 fuma duwei, imparator faytonunun yedek koşum atlarından sorumlu görevlidir. Yıllık 2.000 dan maaş alıyordu. (HS, 19/a. bölüm, s. 739).

${ }^{57}$ guanglu dafu, saray danışmanı. aylık 2.000 dan geliri vardı (HS, 19/a, s. 727; Hucker, age, p. 288). İmparator iç kapıları muhafızları teşkilatına bağlıydı. Eskiden bu makamın ismi zhong dafu 中大夫 idi ve görevi sarayda çeşitli meselelerin görüşülmesi idi, yani bir nevi sarayda danışman kurulunun üyesi idi. MÖ. 104'te zhong dafu makamının ismi guanglu dafu olarak değiştirilmiştir (HS, 19/a. bölüm, s. 727; Taskin, 1968, age, s. 141, not. 138).

${ }^{58}$ Ganquan Sarayı, Qin Hanedanı döneminde inşa edilmiş imparator sarayıdır, sonraki dönemde İmparator Wu tarafından eklemeler yapılmıştır. Bu saray imparatorun başkent dışındaki saraylarından biriydi. Sarayın kalıntıları günümüzde Shaanxi ili, Chunhua ilçesinde bulunmaktadır.

${ }^{59}$ Metinde 弄儿 longer, yani imparatoru eğlendiren oğlan şeklinde tabir kullanılmıştır.

${ }^{60} \mathrm{Bu}$ isimdeki 莽 mang karakteri, ma 马 olarak okunmalıdır. Ma Heluo'nun da Hun asıllı olma ihtimali için bkz. Sanping Chen, age, p. 38-41.

${ }^{61}$ Önceki Han Hanedanı döneminde üst düzey memurlardan biriydi. Bkz. Cang Xiuliang 倉修良, Hanshu Cidian 漢書辭典, Jinan: Shandong jiaoyu chubanshe, 1996, p. 270.
} 
Böylece gizlice yalnız başına onların hareketlerini takip ediyor, saray dışındayken onlara eşlik ediyordu. [Ma] Heluo da [Jin] Midi’nin niyetini anlamıştı ve uzun bir süre harekete geçemedi.

$\mathrm{Bu}$ sırada imparator ülkeyi teftişe çıkmış, Linguang Sarayında 林光宫 konaklıyordu. [Jin] Midi, biraz hastaydı ve kulübesinde dinleniyordu. [Ma] Heluo ve [kardeşi Ma] Tong, diğer kardeşi Ancheng 安成 imparatorun geceleyin saraydan çıkışa izin veren belgesini [sahtesiyle] değiştirdiler. Hep birlikte imparatorun habercisini öldürdüler ve askeri birlikleri harekete geçirdiler. Ertesi sabah imparator henüz yataktan kalkmadan [Ma] Heluo saraya geri döndü. Jin Midi [uyanmış] tuvaletteyken birden bire kendisini huzursuz hissetti. Böylece [hemen] saraya [gelerek] imparatorun yatak odasının kapısının önüne oturdu. Bir anda [sarayın] doğu kanadından elbisesinin kolunun içine hançerini saklamış [Ma] Heluo belirdi. [Jin] Midi'yi görünce yerinde donakaldı. [Sonra] hızlı bir şekilde koşarak imparatorun yatak odasına girmeye çalıştı. Ancak [odanın önündeki] kanuna ayağı takılıp yere düştü. Jin Midi, kucaklayarak [Ma] Heluo'yu yakaladı ve "Ma Heluo isyan etti!" diye bağırdı. İmparator, korkuyla yatağından fırladı. [İmparatorun] korumaları [Ma Heluo’yu] öldürmek için kılıçlarını çıkardılar. İmparator [Jin] Midi'nin de [kargaşanın] ortasında kalacağından endişe ettiği için [korumaların] kıpırdamamasını emretti. [Jin] Midi, [Ma] Heluo'yu boğazından yakalayıp Majestelerinin [yatak odasından] dışarı attı. Böylece [Ma Heluo] tutuklandı ve [elleri ayakları] bağlandı. Soruşturmadan sonra [isyancıların] hepsi cezalandırıldılar. Bu nedenle [Jin Midi] imparatora bağlllığı ve sadakati ile ünlendi.

Jin Midi, özgür idaresiyle itaat ederek [imparatora] birkaç düzine yıl hizmet etti ve hiçbir zaman hizmetini ihmal etmedi. ${ }^{62}$ İmparator ona saray kadınlarından 宫女 birisini takdim ettiyse de hiç ona yaklaşmadı. İmparator, Jin Midi’nin kızının saray cariyelerinden 后宫 olmasını istedi, ancak bunu da reddetti. Onun [imparatora karşı] dürüst, samimi ve ihtiyatlı olduğu bu örneklerden görülmektedir. İmparator onun son derece özel ve sira dişı insan olduğunu düşünüyordu. Hastalandığı zaman imparator Huo Guang'a 霍光 ${ }^{63}$ çocuk yaştaki veliahda [devleti yönetme konusunda] yardımcı olmasını istedi. [Huo] Guang da kibarca bunun için [Jin] Midi'nin görevlendirilmesini istedi. Jin Midi şöyle dedi: "Bendeniz yabancı bir ülkenin insanıyımdır. Ayrıca [ben bunu üstlenirsem] Hunlar Han Hanedanı'nı [bundan sonra] ciddiye almazlar." [Ancak] bundan sonra [Huo] Guang'a bu konuda yardımc1 oldu. ${ }^{64}$ Huo Guang, kızını Jin Midi'nin veliaht oğlu [Jin] Shang 赏 ile evlendirdi.

Evvela İmparator Wu'nun vasiyeti ile Ma Heluo isyanını bastırmadaki başarısı için [Jin] Midi'ye Du Markisi 秺侯 unvanı takdim edilmişti. Ancak İmparator [Zhao] henüz çocuk olduğu için [Jin] Midi bu unvanı kabul etmeyi reddetmişti. ${ }^{65}$ Devlet yönetimine yardımcı olarak bir yıldan fazla çalıştıktan sonra [Jin Midi] hastalandı. Başkomutan [Huo] Guang, imparatora [Jin] Midi'ye asalet unvanının takdim edilmesi için istekte bulundu. Böylece [Jin Midi’ye]

\footnotetext{
${ }^{62}$ Metinde 目不忤视 mu bu wushi, yani “gözleri memnuniyetsizlikle bakmadı” şeklinde verilmiştir.

${ }^{63}$ Huo Guang (öl. MÖ. 68), Batı Han Hanedanı döneminin nüfuzlu devlet adamıdır, Jin Midi’nin de dünürüdür. Kendisi Han Hanedanı döneminin ünlü komutanı Huo Qubing’in üvey kardeşi idi. Dasima 大司馬 ve başkomutan 大將軍 gibi yüksek makamları işgal etmiş, çocuk imparator büyüyene kadar naip olarak hükümeti yönetmiştir. MÖ. 74 yılında İmparator Zhao, 21 yaşında vefat ettiğinde de yerine geçecek imparatoru kendisi seçmişti. Ancak uygunsuz davranışlarından dolayı tahta çıkmasından 27 gün sonra onu da indirerek, yerine başkasıyla değiştirmişti. Onun biyografisi için bkz. HS, 68. bölüm, s. 2931-2959.

${ }^{64}$ İmparator Wu, vefatından önce küçük oğlu Liu Fuling'i (sonradan İmparator Zhao) veliahdı ilan etmiş ve ona üç naip atamıştı. Onlar: Huo Guang, Jin Midi ve Shangguan Ze 上官桀 idi.

${ }^{65}$ MÖ. 87 yılında İmparator Wu vefat ettiğinde 8 yaşındaki İmparator Zhao, naiplerin sorumluluğu altındaydı. Her üç naip de onlara İmparator Wu tarafından takdim edilen Marki unvanını reddetmişlerdi.
} 
unvan mührü ve kordonu ${ }^{66}$ hasta yatağında teslim edildi. Ertesi gün de vefat etti. [Saray] onun cenaze töreni ve mezar höyüğü için gerekli olanakları sağladı. [Cenazesine] savaş arabaları birliği eşlik etti, ordu [onun defnedildiği] Maoling 茂陵 tepesine ${ }^{67}$ kadar sıraya dizildi. Ölümünden sonra onursal Jing Markisi 敬侯 (Sayg11 Marki) unvanı takdim edildi.

[Jin] Midi’nin iki oğlu Shang 赏 ve Jian'ın 建 ikisi de sarayda shizhong olarak hizmet ediyorlard1. Onlar İmparator Zhao 昭帝 ile aynı yaştalardı ve gece gündüz onunla birlikteydiler. [Sonrasinda Jin] Shang fengche 奉车, ${ }^{68}$ Jian ise, fuma duwei olarak atandilar. [Jin] Shang babasının Marki unvanını miras alınca kemerinde [soyluluk unvanını simgeleyen] iki kordon taşıyordu. İmparator, General Huo [Guang'a] "Jin kardeşler [aslında geleneklere göre] iki kordon taşıyamazlar değil mi?" diye sorduğunda Huo Guang, "[Jin] Shang babasının Marki unvanının mirasçısı, hepsi bu," diye cevap vermişti. İmparator tebessüm ederek "Ancak kime Marki unvanının verileceğine biz karar veririz, öyle değil mi?" deyince de [Huo] Guang "Merhum imparator [babanızın] kararnamesine göre, kim başarılı ise Marki unvanı ona takdim edilir,” dedi. Bu sırada İmparator Zhao ve Jin kardeşler 8-9 yaşlarında idiler.

İmparator Xuan 宣帝 tahta çıkınca [Jin] Shang'1 taipu 太仆 ${ }^{69}$ olarak atadı. Huo [Guang] ailesinin [imparatora karşı darbe planının] ilk belirtileri ortaya çıktığında [Jin] Shang [bu aileden olan] eşinden boşanmak için dilekçe gönderdi. Sonunda imparator ona merhamet etti ve [Huo ailesinin hepsi idam edildiğinde] sadece o affedildi. İmparator Yuan 元帝 döneminde ise, [Jin] Shang, guanluxun 光禄勋 ${ }^{70}$ olarak atand1. Öldüğünde ise, oğlu olmadığından dolayı [miras kalan topraklar ve unvanlar] devletçe geri alındı. Yuanshi 元始 [saltanat devresinin] ortasında mirasçısı olmayanların toprakları ve unvanları [başka akrabalarına] takdim edildiği zaman [Jin] Jian'ın torunu [Jin] Dang'a Du Markisi 秺侯 unvanı takdim edilerek [Jin] Midi sülalesinin devam etmesi sağlandi.

Evvela [Jin] Midi Han Devleti'ne küçük kardeşi Lun ile birlikte teslim olmuştu. Onun ikinci ismi Shaoqing 少卿 idi ve imparator sarayında lang 郎 $^{71}$ olarak hizmet ediyordu. Ancak erken yaşta vefat etti. [Jin] Midi'nin iki oğlu önemli mevkilere geldi, ancak torunları onlar kadar başarılı değillerdi. Tersine [Jin] Lun'un soyundan gelenler başarılı olmaya başladılar. [Jin]

${ }^{66}$ 印绶 yinshou, makamı ifade eden kordonlu mühür.

${ }^{67}$ MÖ. 139 yılında İmparator Wu tarafından kendi mezar yeri olarak seçildikten sonra Wei Irmağı'nın sol kıyısında, günümüzdeki Xi'an şehrinin 30-40 km. batısında bulunan mevkiye bu isim verilmiştir (bkz. Huan Kuan, age, 1. bölüm).

${ }^{68}$ Kaynaklarda bu makam hakkında bir bilgi bulunmamaktadır. Ancak fengche lang 奉車郎 veya fengche duwei 奉車都尉 makamları için bkz. Hucker, age, p. 212.

${ }^{69}$ taipu, Han Hanedanı döneminde imparatorun atları ve arabalarından sorumlu saray görevlisidir. Osmanlı'da bunlara imrahor denilirdi. Devlet meraları ve atlardan ve orduya at sağlanmasından da sorumluydu (HS, 19/a. bölüm, s. 729). Rus araştırmacı Bokşçanin'e göre, imparator ahırından sorumluydu (A. A. Bokşçanin, "Oçerk İstorii Gosudarstvennı İnstitutov Kitayskoy İmperii”, Fenomen Vostoçnogo Despotizma: Struktura Upravleniya i Vlasti, red. N. A. İvanov, Nauka, Moskva 1993, s. 279).

${ }^{70}$ İmparator sarayı iç ve dış kapılarındaki muhafızların idaresinden sorumlu memurdur. Ayrıca, imparatorun kişisel korunmalarından sorumluydu ve maiyetinin hareketlerini takip ederdi. Onun görevi imparatorla kişisel yakınlığı ile belirlenmekteydi. Bu dairede muhafızlar dışında çok sayıda memur vardı (Bokşçanin, age, s. 279).

${ }^{71}$ lang sınıfi, Han Hanedanı'nın siyasî tarihinde önemli bir rol oynamıştır. Qin Hanedanı döneminde imparatorun kişisel koruması (shilang) temelinde ortaya çıkan bu sınıfın çeşitli görevleri vardı ve imparatorun kişisel hazinesinden sorumlu daireye bağlıydılar. İmparator sarayı mektebi mezunları dışında bu makama asilzadeler ve üst düzey memurların çocukları da alınıyordu. MÖ. 156-141 yılları arasında bu statüye parayla da sahip olunabiliyordu (Bokşçanin, age, s. 332-333, not. 12). Ayşe Onat'a göre, bu Çin sarayında hükümdarın yakın hizmetinde bulunan ve görev bekleyen memurlara verilen bir unvandır. Tam olarak ne işle uğraştıkları belli değildir (Onat, age, s. 79, not. 2). 
Lun’un oğlu [Jin] Anshang 安上, bu sülalede ilk asaletli olup Marki unvanı takdim edilen kişiydi. $^{72}$

Jin Midi, aslen vatanını kaybetmiş bir Hun ${ }^{73}$ idi, dizginlenmiş esir olarak Han [Hanedanı] sarayına gelmişti. Ancak sadık ve saygılı davranışları ile imparatorun sevgisini kazandı. Samimi ve dürüst şekilde imparatora hizmet etti. Mirasçıları olan torunlarının isimleri de imparatora sadakati ile anıldılar. Yedi sülale boyunca saraya hizmet ettiler. Ne güzel bir başarıdır bu!

Sülalenin ecdadı Xiutu [Beyi] altından insan heykeli yapmış ve onu Gök Tanrısına ibadetinde kullanıyordu. Bundan dolayı onlara Jin (altın) soyadı takdim edilmişti.

\section{Sonuç}

Çin tarih yazıcılığında soyadına karşılık yazılan xing 姓 ve shi 氏 karakterleri kullanılmaktadır. Bunlardan xing, anne soyuna işaret ediyorsa shi, baba soyuna işaret eder. Eski zamanlardan beri soy adı Çin'de kişilerin kimliklerini belirler, yani her hangi birisi soyadından yola çıkarak yüzyıllar öncesi köklerine ulaşabilir. Çin toplumunda günümüzde de aynı soyadı taşıyan kişilerin akraba olduklarına dair inanç vardır. Han Hanedanı döneminden itibaren Çin'e yerleşen göçebe halkların temsilcileri de Çin soyadlarıyla kaydedilmeye başlanmıştır. Dolayısıyla Çin kaynaklarında Han Hanedanı sarayında hizmet etmiş Hunlar ve diğer göçebe milletlerin isimleri çokça karşımıza çıkar. Özellikle Han Hanedanı Tarihi'nde kaydedilmiş başarılı hizmetleri için asalet unvanlarına sahip olan kişilerin tablosunda 功臣表 Hun asılll, ancak Çince soyadıyla kaydedilmiş birçok kişiyi görmek mümkündür.

Hun prensi Jin Midi de kaderin cilvesiyle kendisini Çin sarayında bulmuş birisiydi. Başarılılarından dolayı Han imparatorunun takdirini kazanmış, asaletinden ödün vermemiștir ki imparator onu en önemli devlet adamları ve komutanları ile aynı derecede tutmuştu. Sonraki dönemlerde de bu soyadı taşıyan Hun kökenli kişiler tarih sahnesinde sık sık karşımıza çıkmaktadır.

Günümüzde Jin Midi'nin mezarı Xi'an 西安 şehrinden $40 \mathrm{~km}$. uzaklıktaki İmparator Wu'nun mezarının da bulunduğu Maoling mezarlığında bulunmaktadır. Mezarının yüksekliği 11,93 metre, eni 41,2 metredir. Jin Midi’nin sülalesinden geldiklerini düşünen dünyanın farklı ülkelerinden insanlar dönem dönem onun mezarının başında buluşuyorlar. 2015 yılında Çin, Tayland, Güney Kore, Hong Kong gibi ülkelerden Jin sülalesi temsilcilerinden 500 kişi Jin Midi'nin mezarı başında toplanarak atalarına saygı duruşunda bulundular ve 21 defa havai fişek patlamasıyla ecdatlarının 2149. doğum yılını kutladılar. $^{74}$

Her ne kadar Han Hanedanı'na hizmet etmiş olsa bile muhtemelen Jin Midi, tarihte mezarının nerede olduğunu bildiğimiz tek ecdadımız olabilir. Dolayısıyla bu çalışmada ülkemizde onun isminin bilinmesini arzu ettik. İleride bu sülale hakkında daha çok bilgi ortaya çıkacağını ve başka Türk asıllı Çinlileşmiş aileler hakkında da araştırmaların yoğunlaşmasını umut ediyoruz.

\footnotetext{
${ }^{72}$ Bundan sonra Jin Lun sülalesinin hizmet makamları hakkında bilgiler kaydedilmiştir. Asıl çalışma konumuz Jin Midi olduğundan dolayı burada yer almamaktadır.

${ }^{73}$ Metinde 夷狄 yidi şeklinde verilmiştir. Çinliler, merkezî Çin'in etrafını çevirmiş olan yabancı kavimlerden kuzeyde yaşamakta olanlara Di, doğuda yaşayanlara Yi, batıda yaşayanlara Rong, güneydekilere ise, Man ismini vermişlerdir (Baykuzu, age, s. 26). Eskiden iki ayrı kavmin isimleri olan bu karakterler birlikte kullanıldığında genel bir terim olarak kuzeydeki yabancıları ifade eder (İsenbike Togan, Gülnar Kara, Cahide Baysal, Çin Kaynaklarında Türkler, Eski T'ang Tarihi (Chiu T'ang Shu), Türk Tarih Kurumu Yayınları, Ankara 2017, s. 149).

${ }^{74} \mathrm{http} / / / \mathrm{www} . \mathrm{hnhyqd} . \mathrm{com} / \mathrm{news} / \mathrm{hynews} / 125 . \mathrm{html}$ (E.T. 09.01.2020.
} 

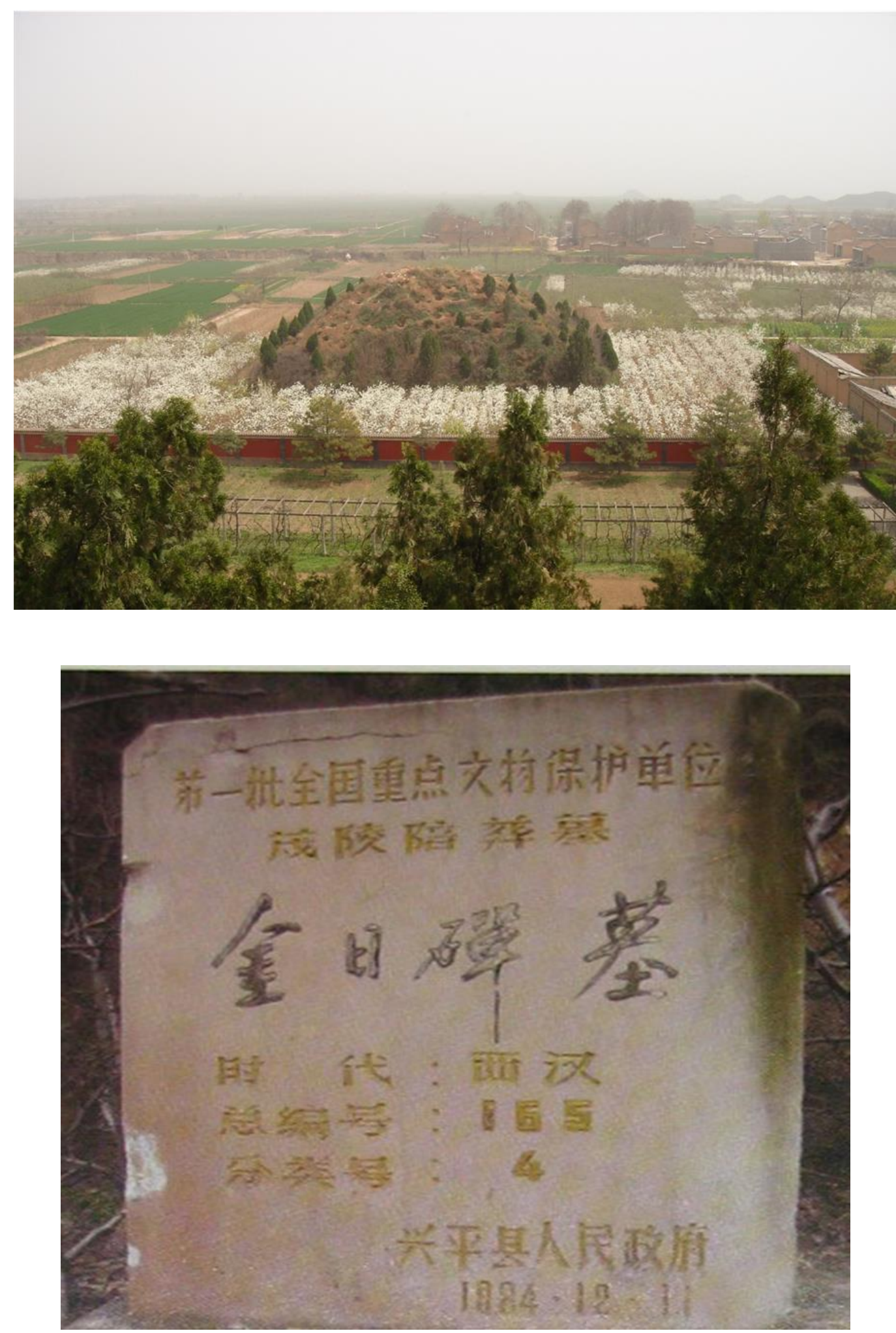

버

HISTORY

STUDIES

1912

Volume 12

Issue 4

August

2020

Jin Midi'nin Çin'deki mezarı ve mezar taşı

http://www.hxtgjs.com/upload/20091016633913081097842264.jpg (E. T. 09.01.2020). 


\section{Kaynakça}

BAN Gu 班固, Han Shu 汉书 (HS), Zhonghua Shuju 中华书局, Beijing 北京 1995, bölümler 19/a, 28/b, 52, 55, 61, 68, 79, 94/a.

BAYKUZU, Tilla Deniz, Asya Hun İmparatorluğu, Kömen Yayınları, Konya 2012.

BOKŞÇANIN, A. A., (1993). "Oçerk İstorii Gosudarstvennıh İnstitutov Kitayskoy İmperii”, Fenomen Vostoçnogo Despotizma: Struktura Upravleniya i Vlasti, red. İvanov, N. A., Nauka Moskva 1993, s. 273-332.

CANG Xiuliang 倉修良, Hanshu Cidian 漢書辭典, Shandong jiaoyu chubanshe, Jinan 1996.

CHEN Sanping, "Two Notes on the Xiongnu Ancestry of the Authors of Han-Shu", Central Asiatic Journal, vol. 55, no. 1, 2011, pp. 33-41.

CHEN Shou 陳壽, San Guo Zhi 三国志, Zhonghua Shuju 中华书局, Beijing 北京 1995.

CORDIER, H., Histoire Generale de la Chine, tome I. Paris 1920.

ÇANDARLIOĞLU, Gülçin, Islam Öncesi Türk Tarihi ve Kültürü, Türk Dünyası Araştırmaları Yayınlar1, İstanbul 2003.

FAN Ye 范晔, Hou Han Shu 后汉书 (HHS), Zhonghua Shuju 中华书局, Beijing 北京1995, bölüm 8.

FANG Xuanling 房玄龄, Jin Shu 晋书, Zhonghua Shuju 中华书局, Beijing 北京 1996, bölümler 97, 101, 116, 117.

HUAN Kuan 桓宽, Yantie Lun 盐铁论 (YTL), bölümler 1, 44. http://www.guoxue.com/zibu/zhajia/yantielun/ytl_044.htm (E. T. 15.01.2020).

HUCKER, C. O., A Dictionary of Official Titles in Imperial China, Southern Materials Center, California 1985.

KAFESOĞLU, İbrahim, Türk Milli Kültürü, Boğaziçi Yayınları, İstanbul 1988.

KARA Gülnar, "Hunlar Tarafından Kurulan Önceki Zhao Veya Han Zhao Devleti Hükümdarlarının Biyografileri (Jin Sülalesi Tarihine Göre)", Türk Dünyası Araştırmaları Dergisi, 110 (216), İstanbul 2015, s. 19-37.

LUO Guanzhong 罗贯中, Sanguo Yanyi 三国演义, bölüm 53. http://www.guoxue.com/minqingstory/sgyy/sgyy_053.htm (E. T. 15.01.2020).

McGOVERN, W. M., The Early Empires of Central Asia: A Study of the Scythians and the Huns and the Part They Played in World History, with Special Reference to the Chinese Sources, The University of North Carolina Press, New-York 1939.

ONAT, Ayşe, Çin Kaynaklarında Türkler, Han Hanedanı Tarihinde Batı Bölgeleri, Türk Tarih Kurumu Yayınları, Ankara 2012.

ONAT, Ayşe, ORSOY Sema, ERCILASUN Konuralp, Han Hanedanı Tarihi, Hsiung-nu (Hun) Monografisi, Türk Tarih Kurumu Yayınları, 2. bask1, Ankara 2015.

OTKAN, Pulat, Tarihçinin Kayıtları’na (Shi Ji) Göre Hunlar, Haz. Giray Fidan, Türkiye İş Bankası Kültür Yayınları, İstanbul 2018. 
ÖGEL, Bahaeddin, "Çin Kaynaklarına Göre Wu-sunlar ve Siyasî Sınırları Hakkında Bazı Problemler”, Ankara Üniversitesi Dil ve Tarih-Coğrafya Fakültesi Dergisi, VI/4, 1948, s. $259-278$.

Rafe de Crespigny, A Biyographical Dictionary of Later Han to the Three Kingdoms (23-220 $A D)$, vol. 19, Brill, Leiden-Boston 2007.

SIMA Qian 司马迁, Shi Ji 史记 (SJ), Zhonghua Shuju 中华书局,Beijing 北京 1996, bölümler $30,108,110,111,123$.

TASKİN, V. S., Materialı Po İstorii Syunnu, Nauka, Moskva 1968.

TOGAN, İsenbike, KARA, Gülnar, BAYSAL, Cahide, Çin Kaynaklarında Türkler, Eski T'ang Tarihi (Chiu T'ang Shu), Türk Tarih Kurumu Yayınları, 2. baskı, Ankara 2017.

TÜRKER, Nurcan, Han Hanedanlığl Döneminde Hunlarla Yürütülen Heqin Politikasl (Akrabalık İle Sağlanan Barış Politikası) ve Sonuçları, (Ankara Üniversitesi Sosyal Bilimler Enstitüsü, Yayımlanmamış Doktora Tezi), Ankara 2013.

VYATKİN, R. V., Muzei i Dostoprimeçetel'nosti Kitaya, Nauka, Moskva 1962.

WEI Shou 魏收, Wei Shu 魏书 (WS), Zhonghua Shuju 中华书局, Beijing 北京 1995, bölüm 4/a.

WEI Zheng 魏徵, Sui Shu 隋书 (SS), Zhonghua Shuju 中华书局, Beijing 北京 1994, bölüm 84.

YAO Weiyuan 姚薇元, Bei Chao Hu Xing Kao 北朝胡姓考, Zhonghua Shuju 中华书, Beijing 北京 1962.

YILDIRIM, Kürşat, Bir Zamanlar Türk Idiler, Türk Kökenli Çin Aileleri, Ötüken Yayınları, İstanbul 2017.

Zhongguo Lishi Ditu Ji 中国历史地图集 (1985). Ed. Tan Qixiang 谭其谼, II, Shanghai 1985. 